\title{
NECESSIDADE HISTÓRICA E AÇÃO HUMANA EM MORTE E VIDA SEVERINA*
}

\author{
HISTORICAL NECESSITY AND HUMAN ACTION \\ IN MORTE E VIDA SEVERINA
}

Djalma Agripino de Melo Filho**

FILHO, D. A. M.: 'Historical necessity and human action in Morte e vida severind'. História, Ciências, Satide - Manguinhos, III(3):409-424, Nov. 1996-Feb. 1997.

Using the essential elements of tragic action described in Aristotles Poetics, the text compares João Cabral de Melo Neto's Morte e vida severina to Sophocles Oedipus rex with the purpose of bringing to light the tension that exists between human necessity and buman action. It is an eminently epidemiological fact that draws a link between these two works. In Morte e vida severina, the causa efficiens behind Severino's decision to migrate is a famine; in Oedipus rex, a plague afflicting the inhabitants of Thebes is the event that hastens discovery of king Lainuss true assassin. It is a reflection on the finalis and formalis causes behind Severino's and Oedipus's movements and on the essential elements of tragic action that allows a transitory falsification or, better put, a rejection of the bypothesis that Morte e vida severina is a tragedy, at least not in Aristotelian terms.

KEYWORDS: epidemiology, literature, Greek tragedy, philosophy of bistory.

\section{Introdução}

"Comunicação apresentada ao ciclo de mesasredondas sobre "A condição severina: situação de vida e saúde do povo pernambucano, 40 anos depois da criação de Morle e vida severina de João Cabral de Melo Neto, promovido pela Secretaria de Saúde de Pernambuco e Fundação Joaquim Nabuco. Recife, $25,28,29$ e 30 de agosto de 1995.

**Mestre em saúde comunitária e assessor da Secretaria de Saúcle de Pernambuco. Rua Nunes Machado, 119/603 50050-590 Recife - PE
Há quarenta anos, João Cabral de Melo Neto concluía Morte e vida severina. O que teria um epidemiologista a dizer sobre o famoso poema, que também constitui um auto de natal pernambucano? Certamente, há em suas entrelinhas uma análise epidemiológica da situação dos 'severinos' pernambucanos, ou mesmo nordestinos, das décadas de 1950 e 1960. Todavia, isso não conduz à conclusão de que a mais célebre obra cabralina seja uma epidemiologia em versos. Aristóteles (1991, p. 201) diz que "se alguém compuser em verso um tratado de medicina ou de física, esse será vulgarmente chamado 'poeta'; na verdade, porém, nada há de comum entre Homero e Empédocles, a não ser a metrificação: aquele merece o nome de 'poeta', e este, o de 'fisiólogo', mais do que o de poeta".

Embora haja algum sentido na distinção feita pelo filósofo grego, João Cabral de Melo Neto não gosta de ser tratado como poeta. Diz ele (apud Campedelli e Abdala Jr., 1982, p. 3):

"A coisa que me dá mais raiva é alguém me chamar de poeta. Chegam ao cúmulo de me escrever cartas endereçadas 'ao poeta João Cabral de Melo Neto'. Tenho vontade de devolver tudo com 
um bilhete: 'não é aqui'. Ninguém escreve ao engraxate Fulano de Tal ou ao romancista Jorge Amado! O funcionário da embaixada vem me entregar a carta e eu sinto aquele ar de ironia. Por que poeta? Poeta não tem isenção nenhuma. Nem imunidade."

Talvez esteja expressa aí uma necessidade de demarcação, embora de uma forma bastante brusca. Uma vez que o próprio senso comum concebe o poeta como um sonhador, lema propagado pelo ideário romântico, João Cabral faz questão de afirmar que não acredita em inspiração poética, acentuando assim a presença da razão na sua obra, pois, como enfatiza Roberto Freire, diretor da famosa encenação que arrebatou o Festival do Teatro Universitário de Nancy, em 1965, na França, o escritor "não deixou de utilizar o conhecimento científico nas investigações do processo criador, refletindo em sua obra a dupla aplicação da intuição e do conhecimento" (idem, ibidem, p. 6).

Essa proximidade com a ciência não nos autoriza a aderir ao cientificismo, tratando Morte e vida severina como uma tese sociológica; todavia, não pretendemos abordar o poema através de instrumentos advindos da crítica literária. Os especialistas já o fizeram, e muito bem. Resta-nos, entretanto, uma saída alternativa. Um caminho que busque a tensão entre os pensamentos filosófico e científico, recorrendo, muitas vezes, a regras de verificação ou de falseamento.

O motivo condutor, ou seja, o leitmotiv desta reflexão foi, sem dúvida, o de fazer emergir a antinomia entre necessidade histórica e ação humana que atravessa todo o poema. Inicialmente, iremos estabelecer uma analogia entre a história de Severino, relatada em Morte e vida severina de João Cabral de Melo Neto, e o mito de Édipo, narrado em Édipo rei de Sófocles. É desnecessário dizer que, provavelmente, estamos cometendo um anacronismo, uma vez que o auto de Natal pernambucano se insere na tradição ibérico-medieval. Mas continuemos, por enquanto, neste trilho perigoso.

\section{Emigração e desfecho trágico: laços epidemiológicos unem os dois poemas}

Logo na abertura de ambas as obras, deparamo-nos com uma situação de natureza epidemiológica. No primeiro caso, Severino, fugindo de uma epidemia de fome e utilizando 64 versos, tenta se identificar para o leitor através de um substantivo próprio, mas quase não consegue (Cabral de Melo Neto, 1980, pp. 70-2):

"- O meu nome é Severino,

não tenho outro de pia.

Como há muitos Severinos,

que é santo de romaria,

deram então de me chamar 
Severino de Maria;

como há muitos Severinos

com mães chamadas Maria, fiquei sendo o da Maria

do finado Zacarias.

Mas isso ainda diz pouco:

há muitos na freguesia, por causa de um coronel que se chamou Zacarias e que foi o mais antigo senhor desta sesmaria.

$\cdots$

Mas isso ainda diz pouco

$\cdots$

Mas, para que me conheçam

melhor Vossas Senhorias

e melhor possam seguir

a história de minha vida, passo a ser o Severino

que em vossa presença emigra."

Na verdade, Severino, com S maiúsculo, torna-se, por força de sua própria condição, um substantivo comum ou mesmo um adjetivo. A metonímia forja-se quando se emprega o sinal ou símbolo - severino - pela coisa significada ou simbolizada a condição de retirante. Segundo Benedito Nunes (1971, p. 82), "São severinos todos os retirantes que a seca escorraça do sertão e que o latifúndio escorraça da terra."

Por outro lado, a tragédia de Sófocles principia com uma súplica. O Sacerdote, diante do palácio do rei, pede a Édipo que salve a cidade de Tebas assolada por males (Sófocles, 1993, p. 22):

“...Tebas, de fato, como podes ver tu mesmo, hoje se encontra totalmente transtornada e nem consegue erguer do abismo ingente de ondas sanguinolentas a desalentada fronte; ela se extingue nos germes antes fecundos da terra, morre nos rebanhos antes múltiplos e nos abortos das mulheres, tudo estéril.

A divindade portadora do flagelo da febre flamejante ataca esta cidade; é a pavorosa peste que dizima a gente e a terra de Cadmo antigo, e o Hades lúgubre transborda de nossos gemidos e soluços." 
O coro de anciãos tebanos faz também o seu lamento (idem, ibidem, p. 29):

“...Ah! Quantos males nos afligem hoje!

O povo todo foi contagiado

e já não pode a mente imaginar

recurso algum capaz de nos valer!

Não crescem mais os frutos bons da terra;

mulheres grávidas não dão à luz,

aliviando-se de suas dores;

sem pausa, como pássaros velozes,

mais rápidas que o fogo impetuoso

as vítimas se precipitam céleres

rumo à mansão do deus crepuscular.

Tebas perece com seus habitantes

e sem cuidados, sem serem chorados,

ficam no chão, aos montes, os cadáveres,

expostos, provocando novas mortes.

Esposas, mães com seus cabelos brancos, choram junto aos altares, nos degraus onde gemendo imploram compungidas

o fim de tão amargas provações."

Como podemos constatar, nos excertos supracitados, sobressaem dois objetos nitidamente epidemiológicos, "doentes em população", para utilizar uma expressão de Almeida-Filho (1989). No primeiro caso, isto é, em Morte e vida severina, trata-se de uma epidemia de fome.

Josué de Castro (1992, p. 175), ao dividir o Brasil em cinco áreas - Amazônia, Mata do Nordeste, Sertão do Nordeste, CentroOeste e Extremo Sul, que formam o chamado mosaico alimentar - assinala que as três primeiras são consideradas áreas de fome. Ele ainda faz uma importante diferença quando esclarece que a fome das áreas da Amazônia e da Mata do Nordeste é endêmica, enquanto aquela que flagela o Sertão é epidêmica, ou seja, são "Surtos agudos de fome que surgem com as secas, intercaladas ciclicamente com os períodos de relativa abundância que caracterizam a vida do sertanejo nas épocas de normalidade."

As secas, segundo o mesmo autor (p. 177), "reduzem o sertão a uma paisagem desértica, com seus habitantes sempre desprovidos de reservas, morrendo à míngua de água e de alimentos. Morrendo de fome aguda ou escapando esfomeados, aos magotes, para outras zonas, fugindo atemorizados à morte que os dizimaria de vez na terra devastada."

No segundo caso, ou seja, na tragédia de Édipo, uma peste, de maneira súbita, passa a afligir os habitantes de Tebas. Isso, sem 
dúvida, caracteriza uma epidemia, em seu sentido de "doenças que visitam uma população".

Podemos dizer, em ambos os casos, que as epidemias de fome, em Morte e vida severina, e a de peste, no Édipo de Sófocles, constituem a causa efficiens que desencadeou a emigração de Severino, no primeiro, e apressou o desfecho trágico, no segundo, quando uma sucessão de atos, unidos por necessidade, faz Édipo acreditar que era o culpado pelos dois crimes que mais terror causavam aos gregos antigos: o parricídio e o incesto.

As epidemias também possuem um significado em ambas as situações. Assim teria razão o médico e revolucionário alemão Rudolf Virchow quando afirmava (apud Rosen, 1980, p. 83): "se a doença é a expressão da vida individual sob condições desfavoráveis, a epidemia deve ser indicativa de distúrbios em maior escala da vida da massa".

Não cabe aqui fazer um movimento característico da clínica, partir da doença e buscar suas causas, mas é conveniente, nesse caso, percorrer um caminho, eminentemente epidemiológico, que vai dos determinantes em direção ao risco. Quais seriam, então, os determinantes de ambas as situações epidêmicas? A resposta a essa pergunta implica recorrer a uma reflexão sobre as causas finalis e formalis, no contexto da filosofia da história. Antes de analisá-las, convém, a propósito de nossos objetivos, rever as duas obras a partir da Poética de Aristóteles. O esforço contribuirá para fazer emergir a concepção de necessidade, extremamente importante para compreender a teoria da causalidade.

\section{Os elementos essenciais da ação trágica}

O filósofo grego define, na referida obra (1991, p. 205), tragédia como a "imitação de caráter elevado, completa e de certa extensão, em linguagem ornamentada e com as várias espécies de ornamentos distribuídas pelas diversas partes (do drama), (imitação que se efetua) não por narrativa, mas mediante atores, e que, suscitando o 'terror e a piedade, tem por efeito a purificação dessas emoções"'.

De um modo proposital, vamos selecionar a última parte da definição para poder concluir que as histórias de Severino e de Édipo causam a todos terror e piedade, todavia Aristóteles aprofunda sua análise através dos componentes essenciais da própria tragédia.

Vejamos, pois, quais seriam os elementos mais importantes desse gênero poético. Do ponto de vista qualitativo, a tragédia, na concepção aristotélica, é composta de seis partes: mito, caráter, elocução, pensamento, espetáculo e melopéia. O caráter é o con- 
junto de qualidades da personagem que lhe determinam a conduta adotada numa ação. O pensamento é um recurso utilizado para demonstrar ou refutar algo e suscitar emoções. A elocução é meio de expressão dos pensamentos. A melopéia é "aquilo cujo efeito a todos é manifesto". O espetáculo é a própria encenação (idem, ibidem).

Embora possa parecer, o espetáculo, mesmo sendo uma parte necessária e emocionante, não é a mais importante da tragédia. Aristóteles (idem, ibidem, p. 207) diz que ele é o componente menos artístico e menos próprio da poesia: "a realização de um bom espetáculo mais depende do cenógrafo que do poeta".

Se comparássemos, à luz dos cinco elementos supracitados, Morte e vida severina e Édipo rei, ambas as obras poderiam ser consideradas trágicas, todavia nos resta avaliar a parte mais importante da tragédia que, segundo Aristóteles, constitui a sua própria alma: o mito. Através de sua compreensão, responderemos se a obra cabralina realmente poderia ser considerada uma tragédia.

Além da concepção geral de narrativa, presente na Poética, o mito, do ponto de vista histórico, possui três significados: "forma atenuada de intelectualidade", "forma autônoma de pensamento ou de vida" e "instrumento de controle social" (Abbagnano, 1982, p. 644). À nossa reflexão, interessa apenas a primeira acepção, aquela que foi adotada por Platão e pelo próprio Aristóteles. Ambos os filósofos contrapõem o mito à verdade ou à narrativa verdadeira, mas também o consideram como uma forma aproximada e imperfeita da verdade, ou seja, "a razão em forma de mito".

João Cabral, em um arcabouço histórico, ou seja, a retirada dos severinos em épocas de seca no Sertão, deixa evidenciar resquícios de uma estrutura mítica. Historiador ou poeta? Aristóteles (1991, p. 209) afirma que

"não é ofício de poeta narrar o que aconteceu; é, sim, o de representar o que poderia acontecer, quer dizer: o que é possível segundo a verossimilhança e a necessidade. Com efeito, não diferem o historiador e o poeta por escreverem verso ou prosa (pois que bem poderiam ser postos em verso as obras de Heródoto, e nem por isso deixariam de ser história, se fossem em verso o que eram em prosa) - diferem, sim, em que diz um as coisas que sucederam, e outro as que poderiam suceder."

O filósofo parece contribuir para esclarecer a dúvida. Todavia, contrariando os princípios da lógica formal, a obra de João Cabral forja-se no limite entre o que aconteceu e o que poderia acontecer. Sem dúvida, trata-se de história e poesia. 
Passaremos, agora, a tentar o falseamento da hipótese de que, assim como Édipo rei de Sófocles, Morte e vida severina de João Cabral de Melo Neto seja uma tragédia. Os argumentos advêm das principais características do referido mito trágico.

Fazendo o cotejamento com as duas obras em estudo, vejamos a estrutura do mito trágico, que é a imitação de uma ação completa que constitui um todo. Segundo Aristóteles (1991, p. 207),

“'Todo' é aquilo que tem princípio, meio e fim. 'Princípio' é o que não contém em si mesmo o que quer que siga necessariamente outra coisa, e que, pelo contrário, tem depois de si algo que está ou estará necessariamente unido. 'Fim', ao invés, é o que naturalmente sucede a outra coisa, por necessidade ou porque assim acontece na maioria dos casos, e que, depois de si, nada tem. 'Meio' é o que está depois de alguma coisa e tem outra depois de si."

Todos os atos intermediários da tragédia estão interligados por necessidade ou verossimilhança e tendem, necessariamente, para um final determinado. Considerando esses esclarecimentos, não há dúvida de que Édipo rei seja rigorosamente uma tragédia.

Essa peça, encenada pela primeira vez em 430 a. C., em Atenas, narra aspectos mais importantes da vida de Édipo, filho dos reis tebanos Laio e Jocasta. Em sua juventude, o pai de Édipo tem uma paixão homossexual por Crísipo, chegando a raptá-lo. Como punição, um oráculo anuncia a Laio que seu filho com Jocasta o mataria. Tentando driblar a natureza necessária da anunciação, Laio ordena a Jocasta que entregue o recém-nascido, após perfurar-lhe os pés e amarrá-los, a um pastor para que o mesmo abandonasse Édipo no monte Citeron e ele lá morresse.

O pastor, todavia, movido por piedade, descumpre a ordem e salva a vida do pequeno Édipo, entregando-o a um outro pastor que apascentava os rebanhos de um outro rei chamado Polibo, da cidade de Corinto, casado com Mérope. O casal real, embora desejasse, não tinha filhos, por isso assumiram Édipo como seu próprio filho.

Um dia, em sua maioridade, Édipo sofre um insulto quando é informado de que não é filho legítimo dos reis de Corinto. Tentando verificar a veracidade da informação, parte para Delfos a fim de consultar o famoso oráculo, que nada lhe diz sobre sua ascendência, mas lhe anuncia que matará o pai e se casará com a própria mãe.

Tentando fugir, assim como seu pai legítimo, da maldição oracular, Édipo, pensando ser filho dos reis Polibo e Mérope, decide não voltar a Corinto. Em sua retirada, numa estrada próxima a Tebas, avista um carro puxado a cavalos onde estão um homem idoso e alguns criados. Enquanto aquele de maneira brusca ordena 
a Édipo que deixe o caminho livre para os cavalos, um destes últimos espanca o transeunte, que reage e mata o idoso, sem saber que se tratava de Laio, seu próprio pai.

Prolongando sua viagem, Édipo chega a Tebas onde se encontrava a terrivel esfinge que apavorava a população com seus enigmas. O viajante decifra o enigma e se livra do monstro. Como prêmio, é feito rei de Tebas e se casa com Jocasta, sua própria mãe. Sendo assim, os dois crimes estavam consumados: o parricídio e o incesto (Kury, 1993, pp. 7-18).

A partir deste resumo, podemos assinalar a força da necessidade ligando todos os atos da ação. De nada adiantou o abandono de Édipo pelos reis tebanos, nem o próprio Édipo ter fugido de Corinto a fim de não matar seu suposto pai, a predição do oráculo confirmou-se de forma inexorável.

\section{A história como um rosário de fatos}

Embora sem a mesma intensidade, em Morte e vida severina sobressai uma noção linear de história onde um fato está ligado a outro por necessidade, haja vista a alusão a um rosário onde a linha seria a estrada na qual vai se desenrolando a história de Severino retirante (Cabral de Melo Neto, 1980, pp. 76-7):

"- Antes de sair de casa

aprendi a ladainha

das vilas que vou passar

na minha longa descida.

Sei que há muitas vilas grandes, cidades que elas são ditas; sei que há simples arruados, sei que há vilas pequeninas, todas formando um rosário cujas contas fossem vilas, todas formando um rosário de que a estrada fosse a linha.

Devo rezar tal rosário até o mar onde termina, saltando de conta em conta, passando de vila em vila."

Caso não fosse tão mecanicista ou mesmo linear, trata-se também de uma história teleológica, que tangencia a abordagem hegelianomarxista. Impelido pela própria necessidade histórica, Severino, independentemente de sua vontade, assim como o rio Capibaribe, deveria cumprir sua sina, isto é, chegar ao Recife (idem, ibidem, p. 92): 
“...Sim, o melhor é apressar

o fim desta ladainha,

fim do rosário de nomes

que a linha do rio enfia;

é chegar logo ao Recife,

derradeira ave-maria

do rosário, derradeira

invocação da ladainha,

Recife, onde o rio some

e esta minha viagem se fina."

Ainda em relação à estrutura mítica, Aristóteles (1991, p. 210) chama atenção para a peripécia que é a transformação dos sucessos em seu contrário, de forma necessária ou verossímil e para o reconhecimento que constitui "a passagem do ignorar ao conhecer".

Estes dois elementos estão presentes em Édipo rei de Sófocles, marcadamente na cena em que chega o Mensageiro ao palácio real de Tebas. Ele vem de Corinto para anunciar que os habitantes desta cidade querem fazer Édipo seu rei, já que Polibo havia falecido. Apesar de trazer alegria para Édipo, ele ficará sabendo que não é filho de quem imaginava ser. A partir daí se sucedem vários episódios que farão Édipo reconhecer que ele próprio seria o assassino do próprio pai, o rei Laio (Kury, 1993).

O binômio peripécia-reconhecimento também aparece de certa forma em Morte e vida severina. Ao chegar à zona da mata, Severino acredita ter encontrado a terra de Canaã (Cabral de Melo Neto, 1980, pp. 85-6, 91, 99):

"- Bem me dizia que a terra

se faz mais branda e macia

quanto mais do litoral

a viagem se aproxima.

Agora afinal cheguei

nessa terra que diziam.

Como ela é uma terra doce

para os pés e para a vista.

Os rios que correm aqui

têm a água vitalícia.

Cacimbas por todo lado;

cavando o chão, água mina.

Vejo agora que é verdade

o que pensei ser mentira.

Quem sabe se nesta terra

não plantarei minha sina?" 
Mais tarde, e aí ocorre a peripécia, Severino se desilude:

"- Nunca esperei muita coisa,

digo a Vossas Senhorias.O que me fez retirar

não foi a grande cobiça;

o que apenas busquei

foi defender minha vida

da tal velhice que chega

antes de se inteirar trinta;

se na serra vivi vinte,

se alcancei lá tal medida, o que pensei, retirando,

foi estendê-la um pouco ainda.

Mas não senti diferença

entre o Agreste e a Caatinga,

e entre a Caatinga e aqui a Mata

a diferença é mais mínima."

Finalmente, ocorre a cena do reconhecimento, quando o retirante chega a um dos cais do Capibaribe:

“...E chegando, aprendo que,

nessa viagem que eu fazia,

sem saber desde o Sertão,

meu próprio enterro eu seguia.

Só que devo ter chegado

adiantado de uns dias;

o enterro espera na porta:

o morto ainda está com vida."

Nos versos citados, Severino adquire a consciência da necessidade, reconhecendo assim o seu inexorável fim que a própria história lhe reservou. Aparentemente, nada há o que fazer: a solução é apressar a morte. O tempo aqui, segundo Benedito Nunes (1971, p. 86), é concebido como "desgaste dos seres e das coisas, um tempo destrutivo e não cumulativo, que não se dá como aproximação natural à morte e sim como antecipação dela".

\section{O 'rosário histórico' se quebra antes da derradeira ave-maria}

Até agora os argumentos utilizados não conseguiram falsear a hipótese que considera Morte e vida severina uma tragédia, todavia insistiremos um pouco mais no procedimento de falseamento.

Há características na citada obra cabralina que a distanciam do ideal da tragédia nos moldes aristotélicos. Analisando a situação trágica por excelência, o pensador grego (1991, p. 211-2) diz:

"Como a composição das tragédias mais belas não é simples, mas complexa, e além disso deve imitar casos que suscitam o terror e 
a piedade (porque tal é o próprio fim desta imitação), evidentemente se segue que não devem ser representados nem homens muito bons que passem da boa para a má fortuna — nem homens muito maus que passem da má para a boa fortuna, pois não há coisa menos trágica, faltando-lhe todos os requisitos para tal efeito; não é conforme aos sentimentos humanos, nem despertar terror ou piedade. O mito também não deve representar um malvado que se precipite da felicidade para a infelicidade. Se é certo que semelhante situação satisfaz os sentimentos de humanidade, também é certo que não provoca terror nem piedade; porque a piedade tem lugar a respeito do que é infeliz sem o merecer, e o terror, a respeito do nosso semelhante desditoso, pelo que, neste caso, o que acontece não parecerá terrivel nem digno de compaixão.

Resta portanto a situação intermediária. É a do homem que não se distingue muito pela virtude e pela justiça; se cai no infortúnio, tal acontece não porque seja vil e malvado, mas por força de algum erro; e esse homem há de ser algum daqueles que gozam de grande reputação e fortuna, como Édipo e Tiestes ou outros insignes representantes de famílias ilustres."

O longo excerto citado não deixa dúvidas quanto a estrutura ideal do mito trágico. E esse não é o caso do nosso Severino: não descende de família ilustre e, principalmente, não cometeu erro algum, tal como fez Laio e o próprio Édipo.

Talvez o aspecto pelo qual o poema não possa ser considerado uma tragédia seja revelado na tensão presente em Morte e vida severina entre uma concepção teleológica de história e a possibilidade de o homem construir sua própria história, através das próprias ações.

Há vários trechos no poema onde Severino decide e não somente segue o leito do Capibaribe, ou seja, o leito da história. Em um deles, "o retirante tem medo de se extraviar porque seu guia, o rio Capibaribe, cortou com o verão" (Cabral de Melo Neto, 1980, p. 77-8):

"...Pensei que seguindo o rio eu jamais me perderia: ele é o caminho mais certo, de todos o melhor guia.

Mas como segui-lo agora

que interrompeu a descida?

...

Tenho de saber agora qual a verdadeira via entre essas que escancaradas frente a mim se multiplicam." 
Nesses versos aparece a possibilidade da escolha, ratificando, assim, o que afirma Heller (1989, p. 15): "As alternativas históricas são sempre reais: sempre é possível decidir, em face delas, de um modo diverso daquele em que realmente se decide. Não era obrigatório que o desenvolvimento social tomasse a forma que tomou; simplesmente foi possivel que surgisse essa configuração (ou outra)."

Em outra parte, o cansaço da viagem leva-o a refletir, nos moldes da própria filosofia da história, sobre um possível interregno para procurar trabalho (Cabral de Melo Neto, 1980, p. 79-80, 103-4):

“...Penso agora: mas por que parar aqui eu não podia e com o Capibaribe interromper minha linha? ao menos até que as águas de uma próxima invernia me levem direto ao mar ao refazer sua rotina? $\mathrm{Na}$ verdade, por uns tempos, parar aqui eu bem podia e retomar a viagem quando vencesse a fadiga. Ou será que aqui cortando agora a minha descida já não poderei seguir nunca mais em minha vida?"

Finalmente, a lei da necessidade que impelia Severino para o suicídio é também rompida:

"- Seu José, mestre carpina, que diferença faria se em vez de continuar tomasse a melhor saída: a de saltar, numa noite, fora da ponte e da vida?"

É nesse exato momento que surge o anjo da anunciação, que se dirige ao mestre carpina. Uma mulher desempenha esse papel no auto cabralino:

"- Compadre José, compadre, que na relva estais deitado: conversais e não sabeis que vosso filho é chegado? 
Estais aí conversando

em vossa prosa entretida:

não sabeis que vosso filho

saltou para dentro da vida?

Saltou para dentro da vida

ao dar seu primeiro grito;

e estais aí conversando;

pois sabei que ele é nascido."

Severino desiste de cometer suicídio e passa a observar um outro auto, ou seja, o auto de Natal. Sendo assim, a terceira parte do mito (as outras são a peripécia e o reconhecimento), a catástrofe, descrita por Aristóteles (1991, p. 211), como "uma ação perniciosa e dolorosa, como o são as mortes em cena, as dores veementes, os ferimentos e mais casos semelhantes", deixa de existir e a vida é reafirmada como um valor, distanciando-se, portanto, da ação trágica. Nesse caso, como bem salienta Benedito Nunes (1971, p. 89), "A implosão da vida severina poderá transformarse em explosão." João Cabral (1980, p. 112) escreve:

"- Severino, retirante,

deixe agora que lhe diga:

eu não sei bem a resposta

da pergunta que fazia, se não vale mais saltar fora da ponte e da vida; nem conheço essa resposta, se quer mesmo que lhe diga.

É difícil defender, só com palavras, a vida, ainda mais quando ela é esta que vê, severina; mas se responder não pude à pergunta que fazia, ela, a vida, a respondeu com sua presença viva.

E não há melhor resposta que o espetáculo da vida: vê-la desfiar seu fio, que também se chama vida, ver a fábrica que ela mesma, teimosamente, se fabrica, vê-la brotar como há pouco em nova vida explodida; mesmo quando é assim pequena 
a explosão, como a ocorrida; mesmo quando é uma explosão de uma vida severina."

\section{Conclusão}

Vimos que as epidemias de fome em Morte e vida severina e de peste em Édipo rei constituíram a causa efficiens que desencadeou a retirada de Severino e apressou a investigação do assassinato do rei Laio, todavia, neste texto, nos comprometemos a ir além desse tipo de causação, apelando para outras modalidades aristotélicas de explicação: a causa finalis e a causa formalis. A primeira delas, segundo Heller (1993, p. 209), encontra-se impregnada de volição. Para alguns pensadores, como Leibniz, essa propriedade estava em Deus; para outros, como Hegel ou Marx, estaria na própria história.

A segunda delas, ainda de acordo com a pensadora húngara (idem, p. 221),

"explica os eventos históricos e suas motivações pela estrutura social no quadro em que ocorrem. A causa é concebida como uma totalidade relativa: como uma estrutura de regras totais, como uma instituição, como uma economia, como um sistema político ou, até mesmo, como um sistema de subsistemas interligados. A causa formalis leva em conta mudanças, não pelos eventos, mas pela lógica interna dos sistemas os quais são meramente expressos pelos eventos e pelas vontades dos atores neles implicados."

Vejamos agora nas duas obras em estudo as abordagens das duas causas.

Se, por um lado, a epidemia (causa efficiens) apressou a identificação do assassino de Laio, por outro, esse processo encontrava-se submetido à volição divina, revelada pelo oráculo de Delfos, que, sem dúvida, constituía a causa finalis. É, todavia, através da avaliação da causa formalis que Édipo rei sobressai como a mais perfeita das tragédias, pois todos os episódios que compõem a ação estão interligados para que o desfecho ocorra necessariamente da forma que ocorreu e não de outra.

Em relação a Morte e vida severina, vimos, à luz da Poética de Aristóteles, que faltam ao poema alguns elementos necessários para que o mesmo possa ser caracterizado como tragédia.

Há passagens no poema que tangenciam a concepção estruturalista de história, onde os atores humanos são efeitos de poderosas estruturas, todavia o recurso que compara a história a um rosário se distancia da visão althusseriana, uma vez que o pensador francês concebia o processo histórico sem teleologia ou 
sujeito. Em alguns trechos da obra de João Cabral, citados anteriormente, a causa finalis não é resultado de uma volição divina, mas se encontra na própria história.

A utilização da metáfora do 'rosário' faz realçar nitidamente a causa formalis em sua concepção determinística, ou seja, um grande argumento dedutivo onde a conclusão teria que ser necessariamente, no caso de Severino, um suicídio. Como foi visto, a catástrofe não acontece, sendo assim, a causa finalis desloca-se da história e passa para as mãos humanas que decidem modificar esta história, mesmo dentro de algumas possibilidades também construídas por outras mãos humanas.

A ruptura do nexo necessário, incrustado na causa formalis, realizada pela volição humana (causa finalis) parece ter falseado provisoriamente a hipótese que considera Morte e vida severina uma tragédia. É verdade que o rio Capibaribe chegou ao seu fim, "cumprindo sua sina", mas a última ave-maria rezada no Recife não foi pela morte, mas por uma vida, mesmo que tenha sido uma vida severina.

FILHO, D. A. M.: 'Necessidade histórica e ação humana em Morte e vida severina'. História, Ciências, Saiide - Manguinhos, III(3):409-424, nov. 1996-fev. 1997.

Utilizando os elementos essenciais da ação trágica, descritos na Poética de Aristóteles, o texto põe em confronto Morte e vida severina de João Cabral de Melo Neto e Édipo rei de Sófocles, a fim de fazer emergir a tensão aí existente entre necessidade e ação humana. Revela-se, a princípio, que é um fato eminentemente epidemiológico que estabelece um traço de união entre as duas obras. Na primeira, a causa efficiens da retirada de Severino é uma epidemia de fome; na segunda, uma peste que assola os habitantes de Tebas é o evento que apressa a descoberta do verdadeiro assassino do rei Laio. Mas é a reflexão sobre as causas finalis e formalis, responsáveis pelos movimentos de Severino e Édipo e elementos essenciais da ação trágica, que permitirá, temporariamente, falsear, ou melhor, recusar a hipótese que considera a obra de João Cabral uma tragédia, pelo menos nos moldes aristotélicos.

PALAVRAS-CHAVE: epidemiologia e literatura, tragédia grega, filosofia da história.

\section{REFERENCIAS BIBLIOGRÁFICAS}

Abbagnano, $\mathbf{N}$. 1982

Almeida-Filho, $\mathrm{N}$. 1989

Aristóteles 1991

Cabral de Melo Neto, J. C. 1980

Campedelli, S. Y. e Abdala Jr., B. 1982
Dicionário de filosofia.

$2^{\mathrm{a}}$ ed., São Paulo, Mestre Jou.

Epidemiologia sem nümeros: uma introdução crítica à ciência epidemiológica. Rio de Janeiro, Campus.

'Poética'. Em J. A. M. Pessanha (org.), Os pensadores, São Paulo, Nova Cultural, pp. 197-229.

Morte e vida severina e outros poemas em voz alta. $12^{a}$ ed., Rio de Janeiro, José Olympio.

'Biografia'. Em João Cabral de Melo Neto.

São Paulo, Abril Educação, pp. 3-6. 
Castro, J. 1992

Heller, A. 1993

Heller, A. 1989

Kury, M. G. 1993

Nunes, B. 1971

Rosen, G. 1980

Sófocles 1993
Geografia da fome (o dilema do brasileiro: pão ou aço). $11^{\mathrm{a}}$ ed., Rio de Janeiro, Gryphus.

Uma teoria da bistória.

Rio de Janeiro, Civilização Brasileira.

O cotidiano e a bistória.

$3^{2}$ ed., Rio de Janeiro, Paz e Terra.

'Introdução'. Em A trilogia tebana. $3^{\mathrm{a}}$ ed., Rio de Janeiro, Jorge Zahar Editor, pp. 7-18.

João Cabral de Melo Neto: nota biográfica, introdução critica, antologia, bibliografia. Petrópolis, Vozes.

Da polícia médica à medicina social: ensaios sobre a bistória da assistência médica. Rio de Janeiro, Graal.

Édipo rei. Em A trilogia tebana. $3^{\mathbf{a}} \mathrm{ed}$., Rio de Janeiro, Jorge Zahar Editor, pp. 19-99.

Recebido para publicação em abril de 1996. 